\title{
PRODUÇÃO DE GRAMÍNEAS FORRAGEIRAS INOCULADAS COM Azospirillum brasilense ASSOCIADA À ADUBAÇÃO NITROGENADA
}

\author{
Paulo Vitor Divino Xavier de Freitas ${ }^{1}$; Danilo Augusto Tomazello ${ }^{1}$, Marília Gomes Ismar ${ }^{1}$, Thiago \\ Thiarles Braw André Furlan Romualdo Ângelo Abraãn Lincon Picciuto Maciel ${ }^{1}$, Anderson Eugênio \\ Firmino ${ }^{1}$, Carlos de Melo e Silva Neto², Aldi Fernandes de Souza França ${ }^{3}$
}

1Discente do Curso de Pós Graduação em Zootecnia, Universidade Federal de Goiás; ${ }^{2}$ Professor Dr. Instituto Federal de Goiás; ${ }^{3}$ Professor Dr. Universidade Federal de Goiás

RESUMO: São inúmeros os nutrientes limitantes na produção de pastagens, destacando-se entre eles o nitrogênio, essencial na síntese de proteínas e pigmentos dos tecidos vegetais. A adubação nitrogenada é fundamental no estabelecimento das plantas forrageiras, sendo um dos pontos que mais onera a produção. Assim, fica clara a necessidade de empregar tecnologias que garantam boa produtividade com menor custo possível. Dentre essas tecnologias podemos evidenciar a utilização de inoculantes contendo bactérias diazotróficas, responsáveis por fixarem no solo o nitrogênio atmosférico e, beneficiarem diretamente o desenvolvimento de gramíneas forrageiras. $\mathrm{O}$ uso de inoculantes disponibiliza nitrogênio mediante fixação biológica, estimula a produção de fitormônios (auxinas, giberelinas e citocininas), favorece a solubilização do fósforo indisponível no solo e, auxilia no desenvolvimento do sistema radicular das plantas. Neste artigo de revisão objetiva-se destacar os benefícios da inoculação, em especial trabalhando-se com o Azospirillum brasilense em gramíneas forrageiras. Com base nos trabalhos científicos analisados pode-se concluir que a inoculação de gramíneas forrageiras com azospirillum brasiliense aumenta produtividade e qualidade da pastagem e, quando associada a adubação nitrogenada o incremento na produção é crescente até a dose de $100 \mathrm{Kg}$ de N/ha ${ }^{-1}$. É importante ressaltar que para o sucesso da utilização deste artifício deve-se considerar a espécie vegetal, os tipos de estirpes e quais técnicas de manejo serão utilizadas na implantação da área.

Palavras-chave: adubação, fixação biológica de nitrogênio, formação, pastagem, recuperação 


\title{
PRODUCTION OF FORAGE GRASSES INOCULATED WITH Azospirillum
}

\author{
brasilense ASSOCIATED WITH NITROGEN FERTILIZATION
}

\begin{abstract}
There are many limiting nutrients in pasture production, including nitrogen, which is essential in the synthesis of proteins and pigments in plant tissues. Nitrogen fertilization is fundamental in the establishment of forage plants, being one of the points that most costs the production. Thus, it is clear the need to employ technologies that ensure good productivity at the lowest possible cost. Among these technologies we can highlight the use of inoculants containing diazotrophic bacteria, responsible for fixing the soil to atmospheric nitrogen and directly benefiting the development of forage grasses. The use of inoculants provides nitrogen through biological fixation, stimulates the production of phytonutrients (auxins, gibberellins and cytokinins), favors the solubilization of phosphorus unavailable in the soil, and assists in the development of the root system of plants. This review article aims to highlight the benefits of inoculation, especially by working with Azospirillum brasilense on forage grasses. Based on the scientific studies analyzed, it can be concluded that the inoculation of forage grasses with azospirillum brasiliense increases productivity and pasture quality and, when associated with nitrogen fertilization, the increase in production is increasing up to $100 \mathrm{~kg}$ of N/ ha-1. It is important to emphasize that for the success of the use of this artifice one must consider the plant species, the types of strains and which management techniques will be used in the implantation of the area. Key words: fertilization, biological nitrogen fixation, formation, pasture, recovery
\end{abstract}

\section{INTRODUÇÃO}

No Brasil existe cerca de 100 milhões de hectares cultivados com pastagens e estima-se de que $80 \%$ destas áreas encontra-se em algum estágio de degradação (CORDEIRO et al., 2015). Além de estarem sujeitas a inúmeras variações climáticas como luminosidade, temperatura, pluviosidade, as pastagens também sofrem como a baixa disponibilidade de nutrientes, isso em função da não adoção de práticas agrícolas, como construção de terraços, calagem, adubação de manutenção e rotação de culturas que, com o tempo diminuem a fertilidade química dos solos e contribui para o aumento das áreas degradadas (FACTORI et al., 2017).

Por anos a pecuária vem sendo explorada de forma extrativista, e esta é uma das principais causas pela qual as áreas de pastagens no Brasil estão em sua maioria 
degradadas ou em estágio de degradação. Isso se deve principalmente a diminuição da fertilidade do solo por excesso de extração de nutrientes (COSTA et al., 2010). Manter áreas comprometidas desta maneira prejudica a sustentabilidade do sistema, não fomentando no país a produção bovina a pasto (HUNGRIA et al., 2016). Pensando na produtividade, é preciso intensificar gradativamente os sistemas cultivados com pastagens (LEAL et al., 2017) para alcançar índices produtivos desejáveis, com o menor custo possível (SILVEIRA-JUNIOR et al., 2015; ERASMO et al., 2017). Assim sendo, é recessário recuperar ou reformar as áreas de pastagem degradadas, tornando-se importante o emprego de tecnologias que garantam produtividade satisfatória.

O uso de prática agrícolas como a utilização de fertilizantes ainda não recebe o devido valor, visto que demanda altos custos (PANKIEVICZ et al., 2015). Entretanto a correção do solo via adubação química ou orgânica é fundamental para melhorar a produtividade das pastagens e, por consequência, os indicadores zootécnicos relacionados à produção animal (PARREIRA et al., 2015). Dentre os adubos químicos pode-se destacar os nitrogenados, um dos principais limitantes na produtividade das pastagens (FACTORI et al., 2017), sendo requerido em grandes quantidades pelas plantas. De acordo com a FAO (2017) a demanda mundial de fertilizantes nitrogenados foi crescente no últimos anos e pode chegar a 118.763 mil toneladas até 2020.

A adubação nitrogenada é indispensável para as gramíneas por interferir em suas características estruturais, o que reflete no comportamento ingestivo (por disponibilidade de forragem) e na produção animal por área (PARREIRA et al., 2015). A falta do nitrogênio $(\mathrm{N})$ acarreta redução da produção devido ao prejuízo da síntese de proteínas e pigmentos dos tecidos vegetais relacionados a fotossintese, sendo que isso acontece principalmente em regiões tropicais e subtropicais, onde a concentração de nitrogênio no solo é baixa (LOPES et al., 2013; SKONIESKI et al., 2017).

Diante do exposto, percebe-se que os custos de produção são grandes limitadores, no entanto existem estratégias tecnológicas que visam reduzí-los (SOUZA et al., 2016), e uma delas é a utilização de bactérias diazotróficas associativas, que diminuem significativamente os custos com adubação nitrogenada (HANISCH et al., 2017). 
Se utilizadas de forma correta estas bactérias são capazes de beneficiar as plantas por meio da incorporação de nitrogênio atmosférico no solo, via fixação biológica. Além disso, podem estimular a produção de fitormônios como auxinas, giberelinas e citocininas e solubilizar fósforo (TIEN et al., 1979; SPAEPEN et al., 2009; BASA et al., 2016). Fica notório que a utilização de bactérias inoculantes é uma alternativa promissora para a formação e recuperação de áreas degradadas, tornando sustentáveis as atividades relacionadas e colaborando de forma indireta para redução de gases de efeito estufa (HUNGRIA et al., 2016). Por este motivo, esta revisão de literatura objetiva discorrer sobre a utilização da adubação nitrogenada e do Azospirillum brasilense como inoculante em gramíneas, destacando os benefícios desta prática.

\section{Adubação nitrogenada em gramíneas no Brasil}

Boa parte do nitrogênio contido no solo encontra-se na forma orgânica, seja na matéria orgânica ou como parte de organismos vivos. Por meio de microorganismos presentes do solo os compostos nitrogenados sofrem alterações rápidas e se transformam em moléculas mais simples $\left(\mathrm{NH}_{4}{ }^{+}\right.$e $\left.\mathrm{NO}_{3}{ }^{-}\right)$que são absorvidas pelas plantas em grandes quantidades, o que gera a necessidade de reposição, seja via adubação química ou ou orgânica (SILVA et al., 2010; SCHEFER et al., 2016).

São notórios os ganhos de produção proporcionados pela adubação nitrogenada em gramíneas forrageiras, como observado em vários trabalhos realizados no Brasil (ROSÁRIO, 2013; BERNARDI et al. 2018; MARIANI et al., 2018), com ganhos de fitomassa em função do maior número de perfilhos, maior produção de folhas e expansão do sistema radicular (GALINDO et al., 2018).

Estudos evidenciam o aumento da produção a medida que se aumenta a dose de nitrogênio, entretanto, a eficiência da adubação nitrogenada é inversamente proporcional ao acréscimo das doses de nitrogênio (BERNARDI et al. 2018). A eficiência na utilização do nitrogênio é obtida relacionando-se a produção de matéria seca com dose de nitrogênio aplicada, quanto maior a dose menor a eficiência de utilização, como mostra o trabalho de Costa et al. (2016). 
Para Beche et al. (2014) o aumento da eficiência de utilização do nutriente é essencial para garantir produção sustentável. Boa parte do nitrogênio aplicado é perdido no ambiente (volatilização, desnitrificação e lixiviação), o que por consequência reduz a produção e causa danos ambientais (SILVA et al., 2013; ROSÁRIO, 2013; PARREIRA et al., 2015). Se considerar a forma da utilização da adubação nitrogenada, associados a adubação mineral ou associado a matéria orgânica, as perdas para o ambiente podem ser maior. Dentre as alternativa para diminuir a utilização de adubos nitrogenados é o uso de bactérias diazotróficas, capazes de fixar nitrogênio atmosférico no solo e, garantir altas taxas de produtividade (HUNGRIA et al., 2010), como será evidenciado nas próximas seções.

\section{Fixação biológica de nitrogênio}

Cerca de $80 \%$ do ar atmosférico é composto por nitrogênio, que na forma de gás é indisponível para animais e plantas. As principais vias de entrada do $\mathrm{N}$ no sistema terrestre são pela produção de adubos sintéticos nitrogenados, como a uréia, obtida pelo processo industrial de Haber-Bosh, por mecanismos naturais, como é o caso dos raios (descarga elétrica atmosférica) e pela fixação biológica nas formas simbiótica ou assimbiótica.

A fixação biológica de $N$ consiste na redução do nitrogênio molecular $\left(\mathrm{N}_{2}\right)$ localizado na atmosfera em um composto nitrogenado na forma de amônia $\left(\mathrm{NH}_{3}\right)$. Alguns seres procariotos são capazes de transformar o elemento em compostos utilizáveis pelas plantas (MARCHETTI \& BARP, 2015). Esses seres são chamados de bactérias dizotróficas associativas ou promotoras de crescimento, capazes de auxiliar o desenvolvimento vegetal de forma limpa e sustentável, uma vez que substitui ou melhora a eficiência da adubação nitrogenada do que fontes oriundas de processos industriais (GIRIALDO et al., 2018).

Conhecer os fatores e processos biológicos que controlam a fixação biológica de nitrogenio é fundamental para produtores e pesquisadores, que ao adquirirem tal conhecimento poderão adequar o manejo, com o intuito de aumentar a eficiência da adubação nitrogenada e incrimentar ganhos às culturas (FAGAN et al., 2007). 


\section{Fixação biológica simbiótica de $\mathbf{N}$}

Não diferente do descrito anteriormente, na fixação simbiótica o $\mathrm{N}_{2}$ atmosferico é reduzido a $\mathrm{NH}_{3}$. Um exemplo específico é a simbiose entre leguminosas e bactérias do gênero Rhyzobium, Bradyrhizobium, Azorizhobium, Photorizhobium, Sinorizhobium (TAIZ \& ZIEGER, 2004). Nesse processo as plantas atráves da sinalização química, estimulando a formação de nódulos radiculares, que quando presentes em maiores quantidades garantem melhor fixação do nitrogênio atmosférico para a planta (MOREIRA et al., 2010). Os nódulos, chamados rizóbios, são células vegetais infectadas pelas bactérias já citadas (BROUGHTON et al., 2006).

A fixação simbiotica tem garantido a disponibilização de nitrogênio biológioco em muitos sistemas agrícolas, visto que a fixação simbiotica fornece a maior parte do $\mathrm{N}$ exigido pelas leguminosas. Entretanto, alguns elementos são fundamentais para que a fixação biológica de $\mathrm{N}_{2}$ seja eficiente, entre eles pode-se destacar a tensão da água, concentração de $\mathrm{O}_{2}$ nos nódulos (o oxigênio inibe a nitrogenase, enzima responsável pela redução do $\mathrm{N}_{2}$ ), tempertura radicular, $\mathrm{pH}$ do solo, salinidade e disponibilidade de nutrientes para a planta, inclusive o próprio nitrogênio e outros elementos minerais (KAMICKER \& BRILL, 1986). Assim, é importante ressaltar que a maioria das espécies simbióticas fixadoras estudadas mostraram algum tipo de sensibilidade à presença do nitrogênio mineral, que em grandes quandtidades pode inibir a fixação de $\mathrm{N}_{2}$ (MOREIRA et al., 2014).

\section{Fixação biológica associativa de $\mathbf{N}$}

Diferentes da associação nos rizóbios, as bactérias associativas promotoras de crescimento ou bactérias de vida livre não formam nódulos e contribuem na rizosfera das plantas (MOREIRA et al., 2010), assim também beneficiam as plantas por meio da incorporação de nitrogênio atmosférico no solo, pela solubilização de fósforo a partir de ácidos orgânicos quando esse estiver em deficiência e, pelo estímulo na produção de fitormônios (TIEN et al., 1979; SPAEPEN et al., 2009; BASA et al., 2016).

Vários diazotróficos (consideradas risobactérias) foram descorbertos e são estudados no país, entre eles os associativos Azospirillum spp. e Burkholderia spp., e os 
endofíticos Herbaspirillum spp. e Burkholderia spp. (MOREIRA et al., 2010). Entre as bactérias diazotróficas mais estudadas com foco na melhoria da produtividade de forragens pode-se destacar o Azospirillum brasilense Tarrand, Krieg \& Döbereiner, 1978, usado como inoculante no cultivo de gramíneas e outras plantas pertencentes a família das Poaceae.

\section{O Azospirillum brasilense}

Descoberto no início dos anos 70, é fruto de estudos realizados por Johanna Dobereiner e pesquisadores da Embrapa Agrobiologia (OKON \& GONZALES, 1994; ROSÁRIO, 2013). Após sua descoberta, passou a ser pesquisado em várias partes do mundo e apresentou respostas satisfatórias para o sistema de produção (ROSÁRIO, 2013). Os Azospirillum colonizam o interior e a superfície das raízes, sendo denominados diazotrofos endofíticos facultativos (BALDANI et al., 1997). Além de fixar nitrogênio pode auxiliar o desenvolvimento da planta devido a solubilização do fósforo, na produção de hormônios promotores de crescimento (auxinas, giberelina e citocinina) e, estimular o metabolismo das raízes (SPAEPEN et al., 2009).

Os microrganismos citadoa acima, quando em deficiência de fósforo, são capazes de solubilizar fósforo mineral insolúvel pela liberação de fosfatases (para liberar o fósforo orgânico) ou produzir ácidos orgânicos (para libertar fósforo inorgânico). Segundo Nakao et al. (2018), o Azospirillum brasilense beneficia as gramíneas auxiliando no desenvolvimento radicular que por consequência favorece o aproveitamento da superfície do solo para absorção de água e nutrientes. Isso reforça resultados encontrados por Aguirre et al. (2018) que ao usarem Azospirillum brasilense favoreceram o desenvolvimento das plantas de Cynodon (Croastcross) durante o verão do segundo ano de produção, um ano após sua utilização.

Em estudos realizados na Florida, Smith et al. (1984) encontraram que ao inocular Sorghum bicolor (L.) Moench (cultivar G522) obteve-se aumento significativo na produção de matéria seca (de 11\% para 24\%) e na produção de nitrogênio (de $9 \%$ para 39\%). Em estudos realizados no Brasil, Hungria et al. (2016), ao inocular Urochloa brizantha (Hochst. ex A.Rich.) R.Webster com Azospirillum brasilense encontraram aumento significativo $(4,6 \%)$ na produção de biomassa e quando essa 
foi associada a adubação nitrogenada $\left(40 \mathrm{~kg} \mathrm{~N} / \mathrm{ha}^{-1}\right)$ esse aumento foi ainda maior $(24,7 \%)$.

Resultados semelhantes foram encontrados para Urochloa ruziziensis (R.Germ.\& Evrard) Crins. O acúmulo de nitrogênio na biomassa de ambos genótipos saltou de $351 \mathrm{mg} \mathrm{N} / \mathrm{m}^{2} \mathrm{em}$ plantas que receberam apenas adubação nitrogenada para $717 \mathrm{mg} \mathrm{N} / \mathrm{m}^{2}$ para plantas que receberam adubação nitrogenada associada à inoculação (HUNGRIA et al., 2016), mostrando ser uma prática vantajosa. É importante ressaltar que a inoculação com Azospirillum brasilense pode beneficiar a produção de diferentes culturas em consórcio. Avaliando o efeito da inoculação com Azospirillum brasilense de duas cultivares de sorgo (Rancheiro e A9902), exclusivo ou em consórcio com capim paiaguás, Nakao et al. (2018) encontraram que a inoculação das sementes aumenta a produção de matéria seca disponível para produção de silagem, estando o sorgo em consórcio ou não.

\section{Inoculação}

Sabe-se que vários são os fatores que interferem na colonização das bactérias e que se não considerados podem levar ao insucesso da sua utilização. Para Hungria et al. (2010), a escolha da estirpe bacteriana é fundamental para o sucesso da inoculação. Para Vogel \& Fey (2016), é relevante considerar também o tratamento que essas sementes receberam, visto que algumas soluções fúngicas utilizadas para proteger as sementes contra patógenos estabelecem relações antagônicas com as bactérias fixadoras de nitrogênio.

Outros fatores como a espécie vegetal, tipo de solo e ciclo da cultura também podem influenciar na utilização do inoculante. Em estudos realizados com duas variedades de cana de açúcar, em dois diferentes tipos de solo, durante três anos consecutivos e recebendo três tratamentos (sem adubação, sem adubação com inoculação e apenas com adubação de $120 \mathrm{~kg}$ de nitrogênio há-1) Schultz et al. (2016) encontraram que a produtividade em megagrama $(\mathrm{Mg})$ para colmos das cultivares se comportaram de forma diferente. A inoculação beneficiou a produção apenas de uma das cultivares no terceiro ano (segunda soca) e no solo menos argiloso. 
Considera-se também relevante para o sucesso da inoculação a forma como o inoculante será utilizado. Para alguns a recomendação é que seja misturado a semente apenas no momento do plantio, o que limita sua aplicação em pastagens estabelecidas. Considerando a produção em diferentes estações do ano, Aguirre et al. (2018) inocularam Cynodon (Croastcross) com estirpes Ab-V5 e Ab-V6 de Azospirillum brasilense no primeiro ano de produção (via cova), durante o plantio e reinocularam (por pulverização) no segundo ano. Os autores notaram que a inoculação melhorou o acúmulo de forragem, no entanto a reinoculação via pulverização no segundo ano não influenciou a produção.

\section{Inoculação associada à adubação nitrogenada}

A inoculação por si só pode trazer benefícios, entretanto quando associada à adubação nitrogenada pode proporcionar maior produção de biomassa e maior acúmulo de N no tecido vegetal (HUNGRIA et al., 2016). Estudos realizados em três diferentes lugares, mostram que o acúmulo de nitrogênio na parte aérea de $U$. brizantha e $U$. rusisiensis foi maior quando a adubação nitrogenada foi associada à inoculação com Azospirillum brasilense.

Associar a adubação nitrogenada à inoculação beneficia fortemente a produção de gramíneas. Só no Brasil, a inoculação das principais gramíneas cultivadas poderia gerar uma economia de mais de um bilhão de dólares por ano (ROSÁRIO, 2013). Em estudos realizados com U. decumbens, Fernandes (2016) associou a inoculação com Azospirillum brasilense a diferentes doses de nitrogênio $\left(0,50 \mathrm{kgha}^{-1}, 100 \mathrm{kgha}^{-1}\right.$, $150 \mathrm{kgha}^{-1}$ e $200 \mathrm{kgha}^{-1}$ ). O autor encontrou resultados positivos para desenvolvimento e produção da forrageira, como aumento da altura das plantas, número de perfilhos, produção de massa seca por área, e massa seca das raízes até a dose de $100 \mathrm{kgha}^{-1}$.

Inoculando a cultura do milho, Lana et al. (2012) observaram que sem aplicação de nitrogênio em cobertura, o Azospirillum brasilense aumentou a produção de biomassa seca da cultura em $652,3 \mathrm{~kg} / \mathrm{ha}^{-1}$. Entretanto nota-se que quando a inoculação foi associada a dose de $100 \mathrm{kgha}^{-1}$ de nitrogênio o rendimento de biomassa seca do milho não foi alterada. Esses resultados reforçam os encontrados por Aguirre 
et al. (2018), que ao inocularem Cynodon com Azospirillum brasilense notaram que os ganhos com a inoculação decrescem com o aumento da dose de nitrogênio.

Dentre os estudos apresentados, destaca-se que a relevancia de apresentar o equilibrio entre a utilização de adubação nitrogenada e a utilização dos microorganismos fixadores de nitrogênio. Para cada espécie de graminea é encontrado um ponto ótimo de desenvolvimento da planta com a melhorar interação das bácterias e com a mínima utilização da adubação nitrogenada externa.

\section{CONCLUSÕES}

A inoculação com Azospirillum brasilense em gramíneas pode proporcionar benefícios ao sistema de produção. A inoculação pode ser associada a adubação nitrogenada, entretanto os benefícios da inoculação são inversamente proporcionais a dose de nitrogênio aplicada, sendo quanto maior a dose de nitrogênio, menor o benefício proporcionado pela inoculação, assim torna-se fundamental o entedimento da necessidade da adubação nitrogenada em acordo com a graminea especifica.

\section{REFERÊNCIAS}

AGUIRRE, P. F.; OLIVO, C. J.; RODRIGUES, P. F.; FALK, D. R.; ADAMS, C. B.; SCHIAFINO, H. P. Forage yield of Coastcross-1 pastures inoculated with Azospirillum brasilense. Acta Scientiarum Animal Sciences, Maringá, v.40, n.1, p.1-8, jan./mar. 2018. DOI: http://dx.doi.org/10.4025/actascianimsci.v40i1.36392.

BALDANI, J. I.; CARUSO, L.; BALDANI, V. L. D.; GOI, S. R.; DOBEREINER, J. Recent advances in bnf with non-legume plants. Soil Biolgy and Biochemistry, v.29, n.5-6, p.911-922, jun. 1997. DOI: https://doi.org/10.1016/S0038-0717(96)00218-0.

BECHE, E.; BENIN, G.; BORNHOFEN, E.; DALLÓ, S. C.; SASSI, L. H. S.; OLIVEIRA, R. Eficiência de uso de nitrogênio em cultivares de trigo pioneiras e modernas. Pesquisa Brasileira Agropecuária, Brasília, v.49, n.12, p.948-957, dez. 2014. DOI: http://dx.doi.org/10.1590/S0100-204X2014001200005. 
BERNARDI, A.; SILVA, A. W. L.; BARETTA, D. Estudo metanalítico da resposta de gramíneas perenes de verão à adubação nitrogenada. Arquivo Brasileiro de Medicina Veterinária e Zootecnia, v.70, n.2, p.545-553, 2018. DOI: http://dx.doi.org/10.1590/1678-4162-9501.

BROUGHTON W, J.; HANIN, M.; RELIC, B.; KOPCIÑSKA, J.; GOLINOWSKI, W.; SIMSEK, S.; OJANEN-REUHS, T.; REUHS, B.; MARIE, C.; KOBAYASHI, H.; BORDOGNA, B.; LE QUÉRÉ, A.; JABBOURI, S.; FELLAY, R.; PERRET, X.; DEAKIN, $W$, J. Flavonoid-inducible modifications to rhamnan $O$ antigens are necessary for Rhizobium sp. strain NGR234-legume symbioses. Journal of Bacteriology, v.188, n.10, p.3654-3663. 2006. DOI: 10.1128/JB.188.10.3654-3663.2006.

CORDEIRO, L. A. M.; VILELA, L.; MARCHÃO, R. L.; KLUTHCOUKI, J.; MARTHAJÚNIOR, G. B. Integração Lavoura-Pecuária e Integração Lavoura-Pecuária-Floresta: Estratégia pra Intensificação Sustentável do Uso do Solo. Cadernos de Ciência \& Tecnologia, Brasília v.32, n.1/2, p.15-53, jan./ago. 2015.

COSTA, K. A. P.; FAQUIN, V.; OLIVEIRA, I. P. Doses e fontes de nitrogênio na recuperação de pastagens do capim-marandu. Arquivo Brasileiro de Medicina Veterinária e Zootecnia, v.26, n.1, p.192-199, jan. 2010.

COSTA, N. L.; PAULINO, V. T.; MAGALHÃES, J. A.; RODRIGUES, B. H. N.; SANTOS, F. J. S. Eficiência do nitrogênio, produção de forragem e morfogênese do capimmassai sob adubação. Nucleus, v.13, n.2, out. 2016. DOI:10.3738/1982.2278.1695.

ERASMO, E. A. L.; GONÇALVES, R. C.; MATA, J, F.; OLIVEIRA, V. A.; BENÍCIO, L. P. F. Growth of Brachiaria brizantha planted at diferente densities and seasons in Santa Fé system with a culture of soybean. Emirates Journal of Food and Agriculture, v.29, n.9, p.658-663, Out. 2017. DOI: https://doi.org/10.9755/ejfa.2017.v29.i9.108. 
FACTORI, M. A.; SILVA, P. C. G.; GONÇALVES, D. M.; SCATULIN-NETO, A.; MARATTI, C. H. Z.; TIRITAN, C. S. Produtividade de massa de forragem e proteína bruta do capim mombaça irrigado em função da adubação nitrogenada. Colloquium Agrariae, v.13, n.3, set./dez. 2017. DOI: 10.5747/ca.2017.v13.n3.a173.

FAGAN, E. B.; MEDEIROS, S. L. P.; MANFRON, P. A.; CASAROLI, D.; SIMON, J.; DOURADO-NETO, D. LIER, Q. J. V. SANTOS, O. S.; MÜLLER, L. Fisiologia de fixação biológica do nitrogênio em soja - Revisão. Revista da Faculdade de Zootecnia e Veterinária e Agronomia, v.14, n.1, p.89-106. 2007.

FERNANDES, J. S. Azospirillum brasilense e adubação nitrogenada na Brachiaria decumbens. 2016. 49f. Dissertação (Mestrado em Agronomia) - Universidade Federal da Grande Dourados, Dourados, 2016.

FOOD AND AGRICULTURE ORGANIZATION OF THE UNITED NATIONS (FAO). Word Fertilizer trends and outlook to 2020. Rome: FAO, 2017. Disponível em: $<$ http://www.fao.org/3/a-i6895e.pdf>.

GALINDO, F. S.; BUZETTI, S.; TEIXEIRA- FILHO, M. C. M.; DUPAS, E.; CARVALHO, F. C. Manejo da adubação nitrogenada no capim-mombaça em função de fontes e doses de nitrogênio. Revista de Ciências Agrárias, v.41, n.4, p.900-913. 2018. DOI: http://dx.doi.org/10.19084/RCA18131.

GIRIALDO, J. G.; FRANCO, G. M. R.; VANEGAS, N. F. G.; RODRIGUEZ, A. H. Bactérias diazotróficas con actividad promotora del crecimiento vegetal en Daucus carota L. Revista Ciência y Agricultura, Tunja, v.15, n.1, p.19-27, jan./jun. 2018. DOI: https://doi.org/10.19053/01228420.v15.n1.2018.7753.

HANISCH, A. L.; BALBINOT-JÚNIOR, A. A.; VOGT, G. A. Desempenho produtivo de Urochloa brizantha cv. Marandu em função da inoculação com Azospirillum e doses de nitrogênio. Revista Agro@mbiente, Boa Vista, v.11, n.3, p.200-208, jul./set. 2017. DOI: 10.18227/1982-8470ragro.v11i3.3916. 
HUNGRIA, M.; CAMPO, R. J.; SOUZA, E. M.; PEDROSA, F. O. Inoculation with selected strains of Azospirillum brasilense and $A$. lipoferum improves yields of maize and wheat in Brazil. Plant and Soil, v.331, p.413-425, jan. 2010. DOI: 10.1007/s11104-009-0262-0.

HUNGRIA, M.; NOGUEIRA, M. A.; ARAUJO, R. S. Inoculation of Brachiaria spp. with the plant growth-promoting bacterium Azospirillum brasilense: An environment-friendly component in the reclamation of degraded pastures in the tropics. Agriculture, Ecosystems and Environment, v.221, p.125-131, jan. 2016. DOI: https://doi.org/10.1016/j.agee.2016.01.024.

KAMICKER, B.J.; BRILL, W.J. Identification of Bradyrhizobium japonicum nodule isolates from Wisconsin soybean farms. Applied and Environmental Microbiology, v.51, n.3, p.487-492, 1986. DOI: 0099-2240/86/030487-06\$02.00/0.

LANA, M. C.; DARTORA, J.; MARINI, D.; HANN, J. E. Inoculation with Azospirillum, associated with nitrogen fertilization in maize. Revista Ceres, Viçosa, v.59, n.3, p.399405, mai./jun. 2012. DOI: http://dx.doi.org/10.1590/S0034-737X2012000300016.

LEAL, D. M.; FRANÇA, A. F. S.; OLIVEIRA, L. G.; ARNHOLD, E.; FERREIRA, R. N.; BASTOS, D. C.; BRUNES, L. C. Fracionamento de carboidratos e proteínas da Brachiaria híbrida 'Mulato Il' sob adubação nitrogenada e regime de cortes. Archivos de Zootecnia, v.66, n.254, p.181-188, abr. 2017. DOI: https://doi.org/10.21071/az.v66i254.2320.

LOPES, M. N.; CÂNDIDO, J. D.; POMPEU, R. C. F. F.; SILVA, R. G.; LOPES, J. W. B.; FERNANDES, F. R. B.; LACERDA, C. F.; BEZERRA, F. M. L. Fluxo de biomassa em capim-massai durante o estabelecimento e rebrotação com e sem adubação nitrogenada. Revista Ceres, Viçosa, v.60, n.3, p.363-371, mai./jun. 2013. 
MARCHETTI, M. M.; BARP, E. A. Efeito rizosfera: a importância de bactérias fixadoras de nitrogênio para o solo/planta - revisão. Ignis, Caçador, v.4, n.1, p.61-71, jan./dez. 2015.

MARIANI, L.; MARTINS, L. P.; SILVA, R. L. M.; DALMOLIN, V. R. F.; BRANDÃO, A. A. Produtividade da forrageira panicum maximum cv. mg12 paredão submetido a diferentes níveis de adubação nitrogenada e de diferentes fontes. Connectoin, n.18, p.111-117, 2018.

MOREIRA, V.; JUSTINO, G. C.; CAMARGOS, L. S.; AGUIAR, L. F. Características adaptativas da associação simbiótica e da fixação biológica do nitrogênio molecular em plantas jovens de Lonchocarpus muehlbergianus Hassl., uma leguminosa arbórea nativa do Cerrado. Rodriguésia, v. 65, n.2, p.517-525 abr/jun. 2014. DOI: http://dx.doi.org/10.1590/S2175-78602014000200013.

NAKAO, A. H.; ANDREOTTI, M.; SOARES, D. A. MODESTO, V. C.; DICKMANN. Intercropping Urochloa brizantha and sorghum inoculated with Azospirillum brasilense for silage. Revista Ciência Agronômica, v.49, n.3, jul./set. 2018. DOI: http://dx.doi.org/10.5935/1806-6690.20180057.

OKON, Y.; GONZALES, C. A. L. Agronomic applications of Azospirillum: an evaluation of 20 years worldwide field inoculation. Soil Biol. Biochem, v.26, n.12, p.1591-1601. 1994. DOI: https://doi.org/10.1016/0038-0717(94)90311-5.

PANKIEVICZ, V. C. S.; AMARAL, F. P.; SANTOS,K. F. D. N.; AGTUCA, B.; XU, Y.; SCHUELLER, M. J.; ARISI, A. C. M.; STEFFENS, M. B. R.; SOUZA, E. M.; PEDROSA, F. O.; STACEY, G.; FERRIERI, R. A. Robust biological nitrogen fixation in a model grass-bacterial association. The Plant Journal, v.81, p.907-919, jan. 2015. DOI: 10.1111/tpj.12777.

PARREIRA, L. H. M.; MARTINS, M. E. P.; RIBEIRO, M. M.; SENA-JÚNIOR J. M. efeito da bactéria Azospirillum brasilense na adubação química e orgânica em pastagens 
constituídas deBrachiaria brizantha cv. Marandu. Enciclopédia Biosfera, v.11, n.21, p. 838-850, 2015.

ROSÁRIO, J. G. Inoculação com Azospirillum brasilense associada à redução na adubação nitrogenada de cobertura em cultivares de trigo. 2013. 71f. Dissertação (Mestrado em Agronomia) - Universidade Estadual do Centro-Oeste, Guarapuava, 2013.

SCHEFER, A.; CIPRIANI, K.; CERICATO, A.; SORDI, A.; LAJÚS, C. R. Eficiência técnica e econômica da cultura da soja submetida à aplicação de fertilizantes nitrogenados em semeadura e cobertura. Revista Scientia Agraria, Curitiba v.17, n.2, p.14-20. 2016.

SCHULTZ, N.; PEREIRA, W.; REIS, V. M.; URQUIAGA, S. S. Produtividade e diluição isotópica de $15 \mathrm{~N}$ em cana-de-açúcar inoculada com bactérias diazotróficas. Pesquisa Agropecuária Brasileira, Brasília, v.51, n.9, p.1594-1601, set. 2016. DOI: http://dx.doi.org/10.1590/s0100-204x2016000900059.

SILVEIRA-JUNIOR, O.; SANTOS, A. C.; ROCHA, J. M. L.; FERREIRA, C. L.S.; OLIVEIRA, L. B. T.; RODRIGUES, M. O. D. Implantação de pastagens sob sistema monocultivo e integrado com lavoura utilizando biofertilizante de cama de aviário como adubação de cobertura. Revista Brasileira de Saúde e Produção Animal, Salvador, v.16, n.3, p.499-512, jul./set. 2015. DOI: http://dx.doi.org/10.1590/S151999402015000300003.

SKONIESKI, F. R.; VIÉGAS, J.; MARTIN, T. W.; NORNBERG, J. L.; MEINERZ, G. R.; TONIN, T. J.; BERNHARD, P.; FRATA, M. T. Effect of seed inoculation with Azospirillum brasilense and nitrogen fertilization rates on maize plant yield and silage quality. Revista Brasileira de Zootecnia, v.46, n.9, p.722-730, 2017. DOI: http://dx.doi.org/10.1590/s1806-92902017000900003.

SMITH, R. L.; SCHANK, S. C.; MILAM, J. R.; BALTENSPERGER, A. A. Responses of Sorghum and Pennisetum Species to the N2-Fixing Bacterium Azospirillum brasilense. 
Applied and Environmental Microbiology, v.47, n.6, p.1331-1336, jun. 1984. DOI:0099-2240/84t061331-06\$02.00/0.

SOUZA, F. M.; LEMOS, B. J. M.; OLIVEIRA-JUNIOR, R. C.; MAGNABOSCO C. U.; CASTRO, L. M.; LOPES, F. B.; BRUNES, L. C. Introdução de leguminosas forrageiras, calagem e fosfatagem em pastagem degradada de Brachiaria brizantha. Revista Brasileira de Saúde e Produção Animal, Salvador, v.17, n.3, p.355-364, jul./set. 2016. DOI: http://dx.doi.org/10.1590/S1519-99402016000300003.

SPAEPEN, S.; VANDERLEYDEN, J.; OKON, A. Y. Plant Growth-Promoting Actions of Rhizobacteria. Advances in Botanical Research, v.51, p.283-320, 2009. DOI:10.1016/S0065-2296(09)51007-5.

TIEN, T. M.; GASKINS, M. H.; HUBBELL, D. H. Plant Growth Substances Produced by Azospirillum brasilense and Their Effect on the Growth of Pearl Millet (Pennisetum americanum L.). Applied and Enviromental Microbiology, v.37, n.6, p.1016-1024, may. 1979. DOI:0099-2240/79/05-1016/09\$02.00/0. 